\title{
Energy Performance Monitoring and Analysis of NetZero Energy Homes (NZEHs)
}

\author{
Hong Xian LI $^{1 *}$, Haitao YU ${ }^{2}$, Mustafa GÜL ${ }^{3}$, Mohamed Al-HUSSEIN ${ }^{1}$, Ahmad ALRIFAI ${ }^{1}$ and \\ Yang $\mathrm{LI}^{1}$ \\ ${ }^{1}$ Hole School of Construction Engineering, Department of Civil and Environmental Engineering, \\ University of Alberta, 9105 116th St. NW, Edmonton, Canada, T6G 2W2 \\ ${ }^{2}$ Landmark Group of Builders, 110395 Street SW, Edmonton, Canada, T6X OP8 \\ ${ }^{3}$ Structural Engineering, Department of Civil and Environmental Engineering, University of \\ Alberta, 9105 116th St. NW, Edmonton, Canada, T6G 2W2 \\ "Corresponding author's e-mail: ho8@ualberta.ca
}

\begin{abstract}
Residential building operations consume a considerable amount of energy, especially in coldclimate regions. The National Energy Board of Canada (NEB) analyzed energy consumption in 2011, and found that energy use in the residential sector, including space heating/cooling, hot water heating, lighting, appliances, and other energy-using devices, accounts for $14 \%$ of the total energy consumption nationally. The concept of NetZero-energy homes (NZEHs) has emerged as a solution to reduce the energy demands of residential building operations. Following efforts to develop NZEHs, the actual energy performance of these homes needs to be examined, and sensor technology is capable of measuring this energy consumption in detail. In this research, sensor instrumentation is customized for NZEH projects developed by Landmark Group of Builders in Edmonton, Canada. Data is collected for the first month and following winter months, then the collected data is validated and cleaned and is analyzed in terms of energy consumption, energy generation, and energy balance. Based on the analysis, recommendations for the operation of NZEHs are proposed.
\end{abstract}

\section{KEYWORDS}

Energy performance; energy monitoring; NetZero-energy home (NZEH)

\section{INTRODUCTION}

Energy demand from residential building operations in cold-climate regions has garnered worldwide attention, including in Canada. The NEB (2013) analyzed energy consumption in 2011 by sector considering residential, commercial, industrial, and transportation. It was discovered that energy use in the residential sector for space heating/cooling, hot water heating, lighting, appliances, and other energy-using devices, accounts for $14 \%$ of the total energy consumption, and that the energy demand will increase at an average annual rate of $0.7 \%$ between 2011 and 2035 .

In response to this and other studies, the concept of NetZero energy homes (NZEHs) has emerged as a solution to reduce the energy demand from residential building operations. A $\mathrm{NZEH}$ is defined as a low-rise residential building that consumes approximately the same 
amount of energy that is produced by on-site renewable sources on an annual basis. NZEHs apply highly energy-efficient house designs, and use on-site energy producing technologies to offset the energy demand; NZEHs also aim to achieve a net-zero energy balance between consumption and production on an annual basis during occupancy. Significant efforts have been made to develop NZEHs in Canada and around the world; in North America, associations including the NetZero Energy Home Coalition (NZE) have been established to promote the development and marketing of NZEHs. The NZE supports a long-term vision that all new homes in Canada will be built to consume net-zero energy by 2030 (Government of Canada 2005); the Government of Canada (2005) also announced the NetZero energy healthy housing initiative, which seeks to achieve net-zero energy consumption for residential building operation in Canada.

As a follow-up to efforts made to develop NZEHs, the actual energy performance of these homes needs to be monitored and assessed. Based on reviews of six net-zero energy buildings (NZEBs), five in Canada and one in the United States, Proskiw (2010) has analyzed the best practices of design and construction of NZEBs in Canada; this study considered building envelope, mechanical system, and renewable energy system, and proposed technology solution suites to support this new paradigm. Thomas and Duffy (2013) have investigated the actual energy performance of NZEBs in the New England region of the United States, and the results showed that out of 10 NZEB cases, six attain at least net-zero energy. Musall et al. (2010) have conducted a comprehensive review of more than 280 NZEBs in various countries throughout the world. Their study considered the following information: (1) the distribution of NZEBs by country, where Canada accounted for approximately 30 of the 280 total buildings; (2) energy efficiency of three groups, "small residential building", "apartment building", and "nonresidential building", considering different building components; (3) on-site energy generating technology for three types of buildings, and comparison between primary energy credits and primary energy consumed. In addition to these technical issues, the study of NZEHs entails certain social aspects, such as industry strategies to promote performance and market awareness/acceptance. The NetZero Energy Home Coalition (2013) has hosted a workshop to identify the "path to zero", and summarized the priorities for five groups: (1) policy \& grid, (2) driving market demand, (3) finance \& real estate, (4) education \& tools, and (5) products \& technologies. The National Institute of Standards and Technology (2011) has also organized a workshop to identify and categorize strategies to achieve NZEHs, and proposed guidelines for design, technology \& equipment, home owners, and the building industry.

In general, there exist two methods to monitor the actual energy performance of buildings: (1) meter or utility bills, and (2) sensor technology. Meter or utility bills can be used to collect rough data about energy usage and generation, as exemplified in a study by Thomas and Duffy (2013). However, more energy consumption details, such as the amount of energy consumption for a specific device, need to be investigated; sensor technology is applicable for detailed energy monitoring of this nature. Ridley et al. (2014) have utilized a designed monitoring system to measure the actual performance of two passive houses. Sharmin et al. (2014) have proposed a framework for energy performance monitoring of a building during occupancy using sensor technology; in their study, different types of sensors are utilized to monitor energy consumption, thermal performance of the building envelope, and indoor air quality (IAQ). The sensor data in their study is transmittable, storable, and downloadable, making it useful for energy analysis. 


\section{METHODOLOGY}

Sensor technology is utilized to monitor actual energy consumption for NZEHs, thereby incorporating occupant behaviour; the actual data is used to assess and analyze the energy performance of NZEHs. The inputs of the methodology include NZEH case information, collected raw data, and outdoor temperature. The main processes are: (1) sensor instrument design, (2) actual data collection, (3) raw data validation and cleaning, (4) first-month data analysis with regard to energy generation, energy consumption, and balance, and (5) wintermonths data analysis for energy consumption and distribution. This research is subject to NZEH design specifications, occupant behaviour, and capacity of the solar energy system. The research methodology is demonstrated in Figure 1, which outputs energy consumption, generation, and balance for different months, energy consumption contributor ranking, and recommendations on the operation of NZEHs.

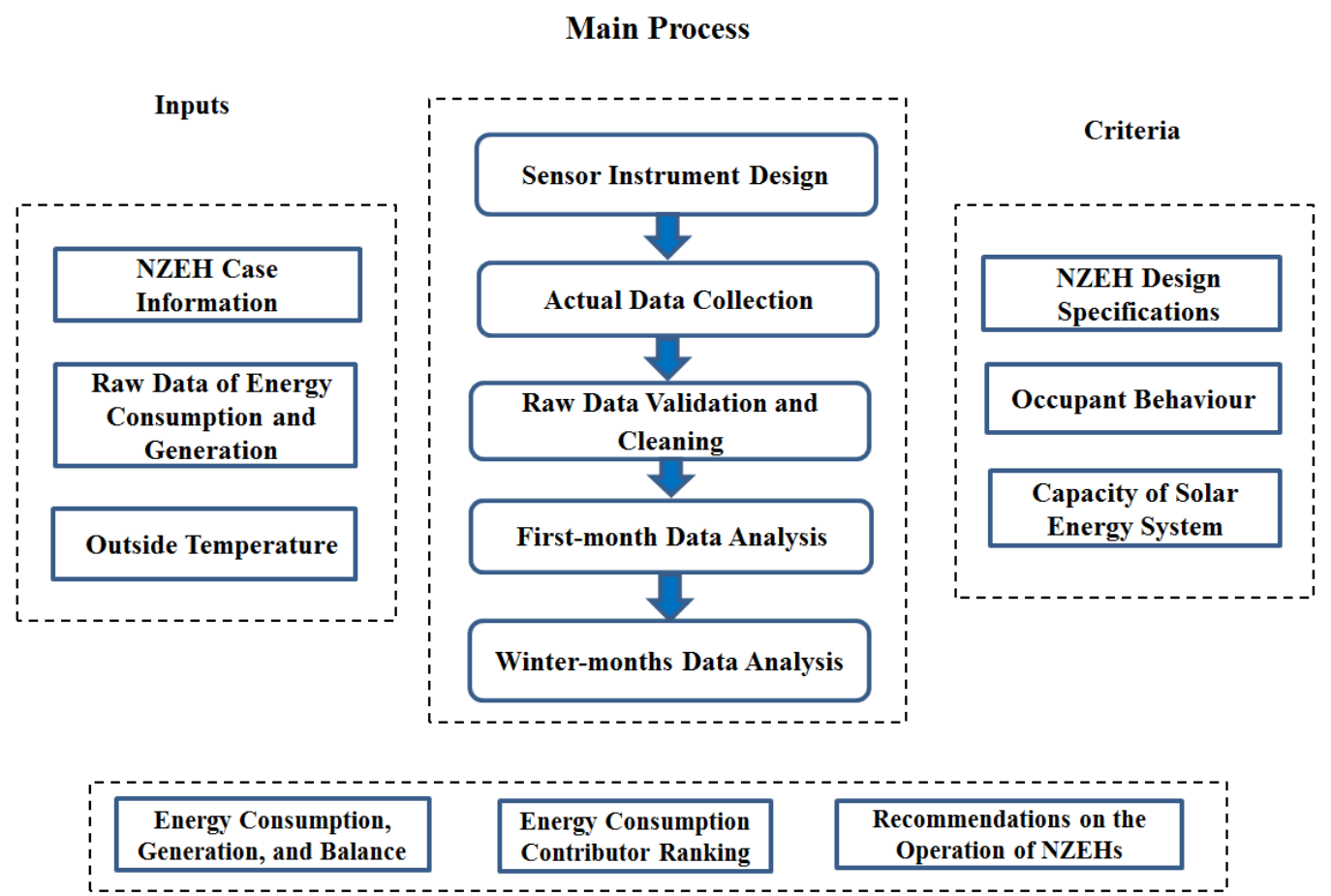

Figure 1. Research methodology

\section{Sensor instrument and measurement}

Different types of sensors are customized and installed to collect the required data. The data collected is stored locally on a single-board computer, and then transmitted to a database server at the University of Alberta via a secured Internet connection. The measurement targets for the case study NZEHs include: (1) electricity consumed by different equipment and appliances, i.e., space heating furnace, hot water tank, heat recovery ventilation (HRV); and (2) indoor and outdoor temperature. To gather data pertaining to the respective measurement targets, different instruments and sensors are customized: (1) Brultech GEM (GreenEye Monitor) with micro-40 current transformer and micro-100 current transformer sensors are used to measure electricity consumption, and (2) Arduino Mini with DHT11 sensors are adopted to monitor temperature. Electricity generation is measured using off-the-shelf products from SMA America, which is a 
comprehensive solar energy service provider. The schematic diagrams of sensor instrument and data transmission are provided in Figure 2, and a channel assignment example of sensor measurement is demonstrated in Table 1.

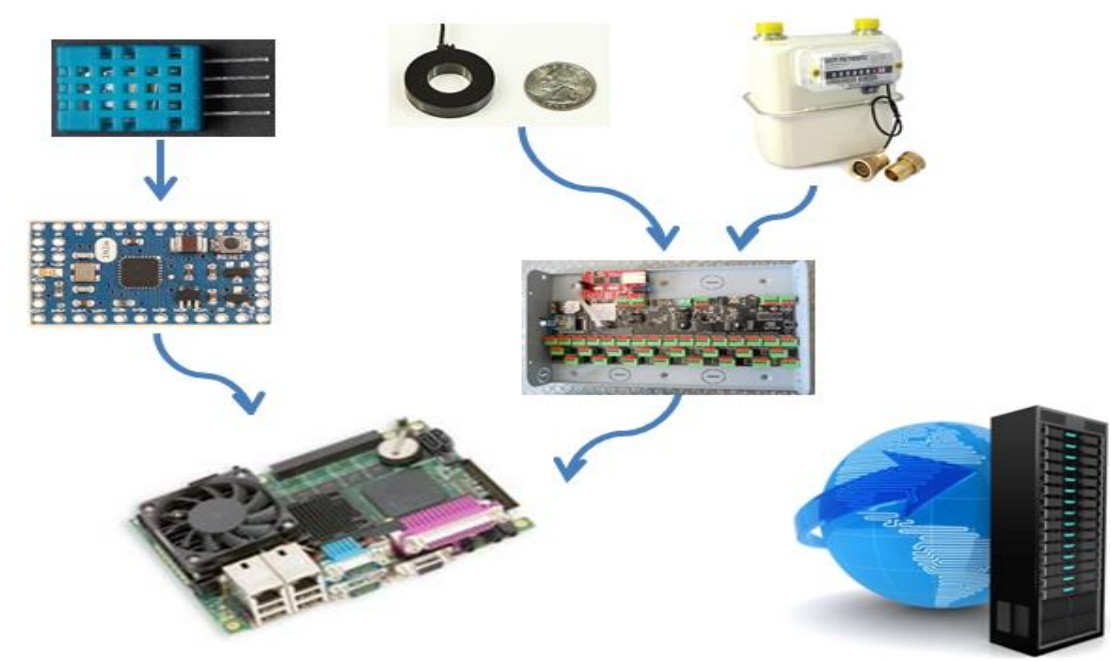

Figure 2. Schematic diagram of data collection and transmission

Table 1. Channel assignment of sensor measurement example

\begin{tabular}{|c|c|c|c|c|}
\hline House Type & Measurement Target & $\begin{array}{c}\text { Instruments and } \\
\text { Sensors }\end{array}$ & Sensor Channel & $\begin{array}{l}\text { Measurement } \\
\text { Detail }\end{array}$ \\
\hline \multirow{24}{*}{$\begin{array}{c}\text { NetZero } \\
\text { Single Family } \\
\text { House }\end{array}$} & \multirow{21}{*}{ Electricity Consumption } & \multirow{21}{*}{$\begin{array}{l}\text { Brultech GEM } \\
\text { (GreenEye } \\
\text { Monitor) with } \\
\text { micro-40 current } \\
\text { transformer and } \\
\text { micro-100 current } \\
\text { transformer } \\
\text { sensors }\end{array}$} & Channel 1 & Main A \\
\hline & & & Channel 2 & Main B \\
\hline & & & Channel 3 & Zuba A \\
\hline & & & Channel 4 & Range B \\
\hline & & & Channel 5 & Fridge A \\
\hline & & & Channel 6 & Exterior Plug B \\
\hline & & & Channel 7 & Condenser A \\
\hline & & & Channel 8 & Range A \\
\hline & & & Channel 9 & Hot Water Tank A \\
\hline & & & Channel 10 & Zuba B \\
\hline & & & Channel 11 & Dryer A \\
\hline & & & Channel 12 & Dryer B \\
\hline & & & Channel 13 & Hot Water Tank B \\
\hline & & & Channel 14 & Zuba B \\
\hline & & & Channel 15 & Washer B \\
\hline & & & Channel 16 & Garburator \\
\hline & & & Channel 17 & Dish Washer A \\
\hline & & & Channel 18 & Zuba A \\
\hline & & & Channel 19 & Island Fridge A \\
\hline & & & Channel 20 & HRV \\
\hline & & & Channel 21 & Condenser B \\
\hline & \multirow[t]{2}{*}{ Temperature } & \multirow[t]{2}{*}{ DS 18B20 } & Channel 22 & $\begin{array}{c}\text { Outdoor } \\
\text { temperature }\end{array}$ \\
\hline & & & Channel 23 & Indoor temperature \\
\hline & Electricity Generation & SMA & NA & \\
\hline
\end{tabular}




\section{CASE STUDY}

A single-family NZEH in Edmonton is used as an example in this research. The floor area of the NZEH case is $2,386 \mathrm{ft}^{2}\left(222 \mathrm{~m}^{2}\right)$, and the insulation value of the roof is R80, with R40 for the main walls. A $13.7 \mathrm{~kW}$ solar photo voltage (PV) system is used for on-site energy generation, mounted on the south-facing roof. The raw data is collected at 30-second intervals, is validated and cleaned, and is analyzed as follows:

\section{First-month data analysis}

For the first month of data collection (Sep. 3 to Oct. 2), the monitored energy consumption and generation data is validated and analyzed from different perspectives and at varying time intervals.

(1) Total energy profile: the total energy profile with regard to energy consumption, generation, and balance for the first month is listed in Table 2, and the energy consumption distribution is illustrated in Figure 3.

Table 2. Total Energy Profile between Sep. 3 and Oct. 2

\begin{tabular}{lcc}
\hline Items & $\begin{array}{c}\text { Energy } \\
(\mathbf{k W h})\end{array}$ & \% \\
\hline PV Generation & $\mathbf{1 3 5 2 . 8 8}$ & \\
\hline Total Electricity Consumption & $\mathbf{9 6 7}$ & \\
\hline Space Heating & 356 & $37 \%$ \\
Hot Water & 163 & $17 \%$ \\
HRV & 73 & $8 \%$ \\
Range & 54 & $6 \%$ \\
Exterior Usage & 54 & $6 \%$ \\
Dryer & 44 & $5 \%$ \\
Main Fridge & 39 & $4 \%$ \\
Dish Washer & 13 & $1 \%$ \\
Washer & 6 & $1 \%$ \\
Others (lighting \& plugs) & 151 & $16 \%$ \\
\hline Balance & $\mathbf{3 8 5 . 5 9}$ & \\
\hline
\end{tabular}

(2) Daily energy profile: the collected data is analyzed here from a daily perspective. The daily total energy consumption, energy generation, and balance are demonstrated in Figure 4, in which positive balance refers to extra electricity that is injected into the grid, and negative balance shows electricity that is drawn from the grid. To display the statistical meaning with regard to energy balance, the average hourly energy profile is plotted in Figure 5, from which it can be concluded that the most energy surplus for the period Sep. 3 to Oct. 2 occurs between 8:00 am and 5:30 pm. If the operation time for some appliances is pre-set during this period, the generated energy will be used directly on-site, and would save the cost difference between injecting and drawing electricity. 


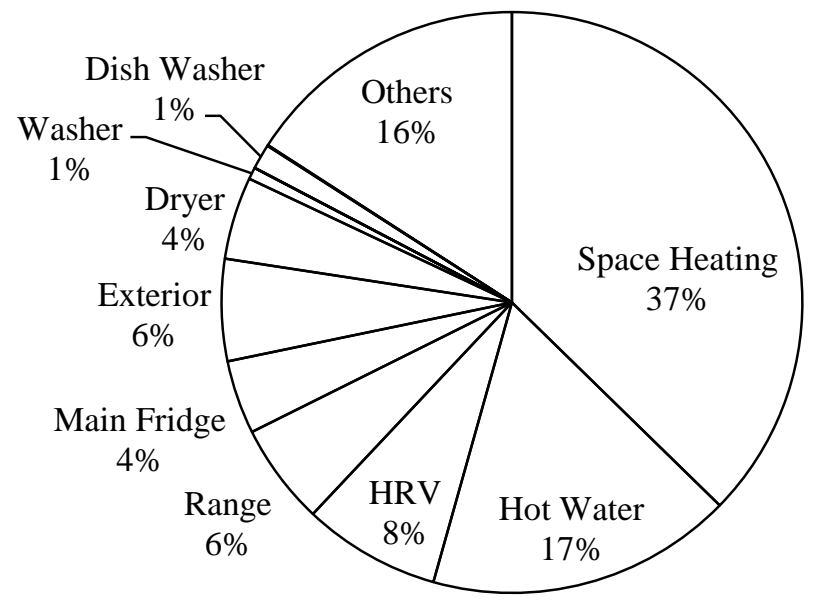

Figure 3. Energy consumption distribution (Sep. 3 to Oct. 2)

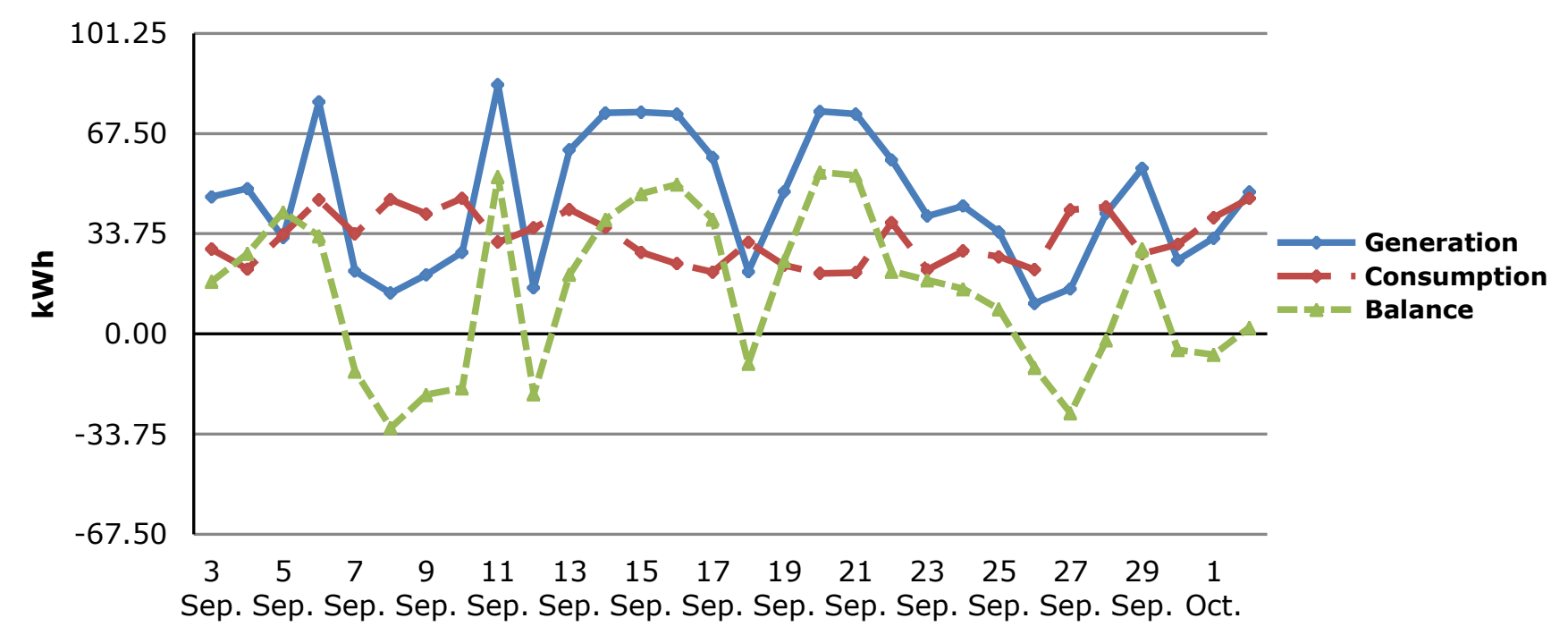

Figure 4. Daily Energy Profile (Sep. 3 to Oct. 2)

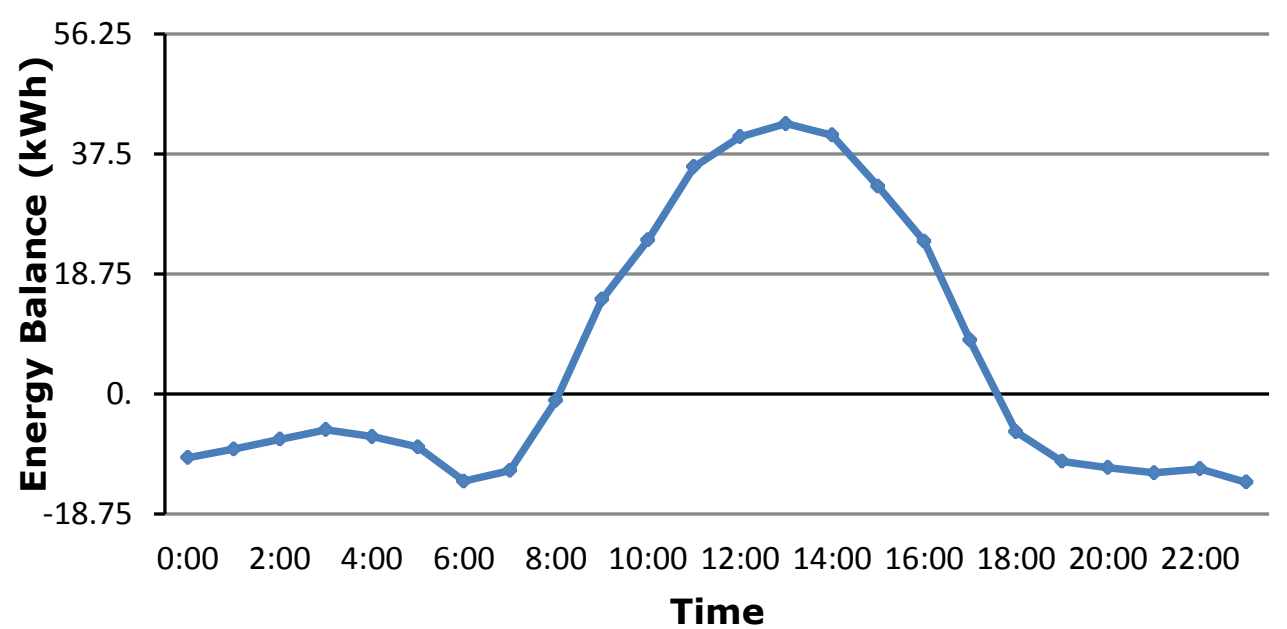

Figure 5. Average Hourly Energy Profile (Sep. 3 to Oct. 2) 


\section{Winter-month data analysis}

In cold regions such as Edmonton, Canada, space heating in winter consumes a large amount of energy, so the collected data is analyzed for the winter season between November 1 and January 31; meanwhile, since no solar energy generation data is accessible at this time, only energy consumption is analyzed as follows:

(1) Daily energy consumption profile and distribution: the daily energy consumption profile is demonstrated with respect to the devices shown in Figure 6. The energy consumption distribution of January is demonstrated in Figure 7 as an example. Between November and January, the largest contributor is space heating, and the second largest is hot water heating. It is also observed in this research that the efficiency of the air-source heat pump drops significantly in low temperature conditions (below $-15^{\circ} \mathrm{C}$ in this case).

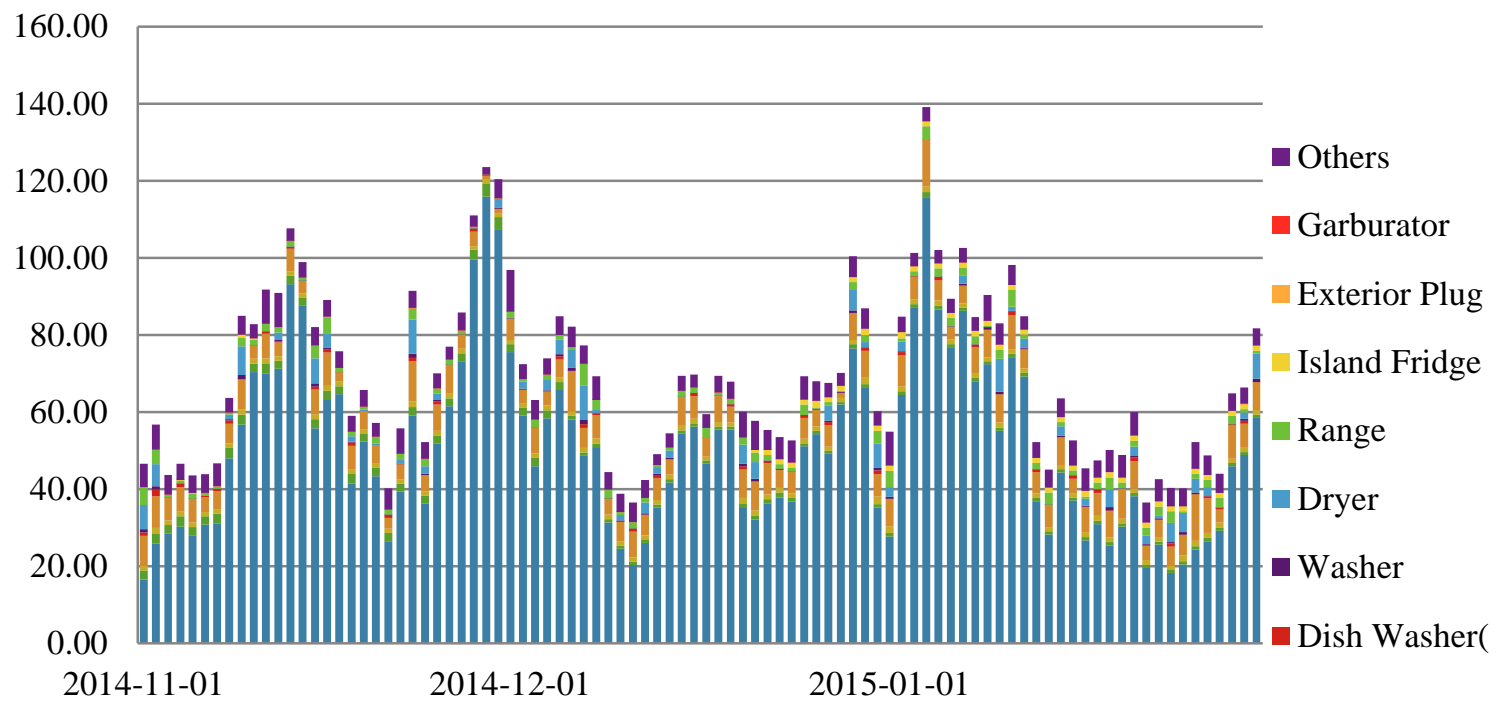

Figure 6. Consecutive-month energy consumption profile (Nov. to Jan.)

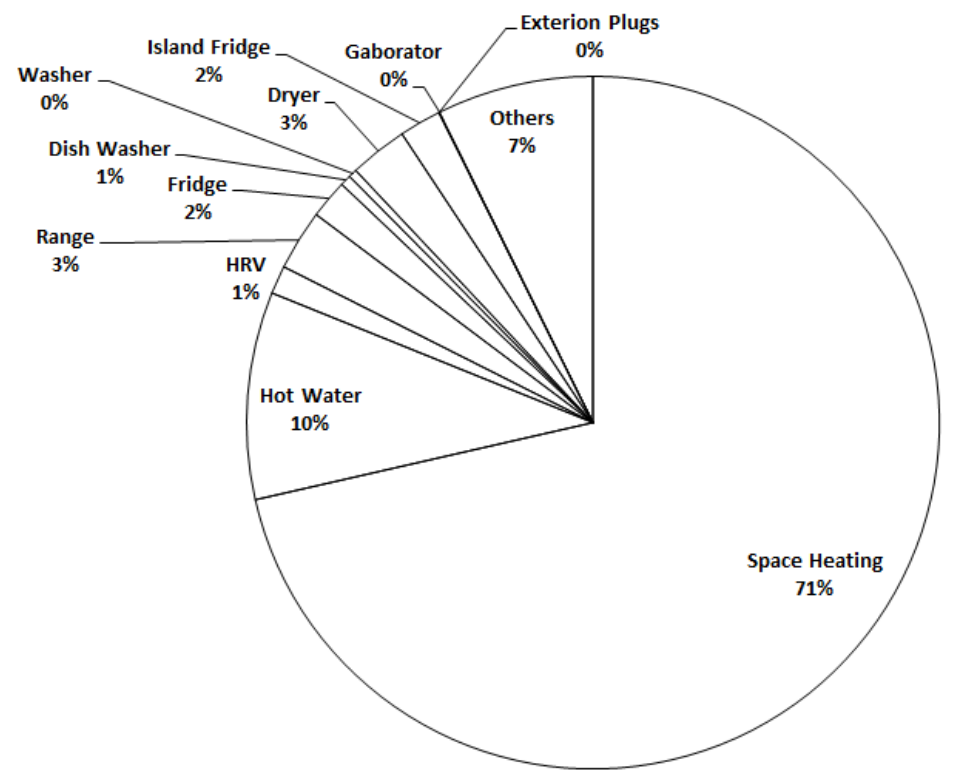

Figure 7. Energy consumption distribution for Jan. 


\section{CONCLUSIONS AND RECOMMENDATIONS}

NZEHs are designed to achieve net-zero energy balance. House location, design scenario, operation approach, and occupant behaviour are all contributing factors that determine whether or not NZEHs are truly net-zero. Based on the monitoring instrument and data analysis presented in this paper, the following conclusions and recommendations are offered:

(1) Except in the winter season, the total energy consumption is mainly determined by occupant activity; e.g., hot water usage, lighting, receptacles, dish washer, washer, and dryer.

Suggestion: To eliminate excess waste of energy, switch power off when possible.

(2) Space heating in winter accounts for more than $70 \%$ of total energy consumption. The energy used for space heating and the operation efficiency of air-source heat pumps are correlated to outside temperature. It is observed in this research that the efficiency of airsource heat pumps drops significantly in low temperature conditions (observed as $-15^{\circ} \mathrm{C}$ in this case).

Suggestion: Use of alternative heating source; e.g., fireplace, when temperature drops below $-15^{\circ} \mathrm{C}$.

(3) To offset energy consumption on site, pre-set some appliances to operate within an energy surplus period, during which period solar PV usually generates rich electricity; then the electricity generated will be used on-site directly, which can save the cost difference between injecting to the grid and drawing from the grid.

In-depth analysis and prediction models for NZEHs will be developed in future research based on the analysis conducted in this paper.

\section{REFERENCES}

National Energy Board (2013). "Canada's energy future: energy supply and demand projections to 2035." <http://www.neb-one.gc.ca/clfnsi/rnrgynfmtn/nrgyrprt/nrgyftr/2009/rfrnccsscnr2009-eng.pdf> (Oct. 12, 2013).

Ridley, I., Bere, J., Clarke, A., Schwartz, Y., and Farr, A. (2014). "The side by side in use monitored performance of two passive and low carbon Welsh houses." Energy and Buildings, 82, 13-26.

Sharmin, T., Gül, M., Li, X., Ganev, V., Nikolaidis, I., and Al-Hussein, M. (2014). "Monitoring building energy consumption, thermal performance, and indoor air quality in a cold climate region." Sustainable Cities and Society, 13, 57-68

Thomas, W. D., and Duffy, J. J. (2013). "Energy performance of net-zero and near net-zero energy homes in New England." Energy and Buildings 67, 551-558.

Musall, E., Weiss T., Voss K., and Lenior, A. (2010). "Net zero energy solar buildings: An overview and analysis on worldwide building projects". <http://www.enob.info/fileadmin/media/Projektbilder/EnOB/Thema_Nullenergie/EuroSun_Conf erence_Graz_2010_Net_Zero_Energy_Solar_Buildingsx.pdf> (Dec. 21, 2013).

Proskiw, G. (2010). "Identifying affordable net zero energy housing solutions." Proskiw Engineering Ltd. <http://www.hme.ca/reports/Identifying_Affordable_Net-ZeroEnergy_Housing_Solutions.pdf> (Dec. 21, 2013). 